\title{
Do we really allow patient decision-making in rotator cuff surgery? A prospective randomized study
}

\author{
Carlos Torrens $^{1 *} \mathbb{D}$, Joan Miquel ${ }^{2}$ and Fernando Santana ${ }^{1}$
}

\begin{abstract}
Background: There is a growing patient interest in being involved in the decision-making process. However, little information is provided on how this information should be structured.

Does it make a difference, in patient treatment decision-making, whether information is given based on the benefits or on the side effects in rotator cuff disorders?

Methods: It is a prospective randomized study that includes patients diagnosed with rotator cuff tears. Patients were randomly allocated to either group A (benefit-inform) or group B (side effect-inform) and were asked to answer the following questions based on their assigned group:

Group A: Your doctor informs you that you have a rotator cuff tear and states that if he/she surgically repairs your cuff tear you will improve and that the cuff remains healed at the 2-year follow-up in $71 \%$ of the cases where surgery is done.

Would you choose surgery? Yes or No

Group B: Your doctor informs you that you have a rotator cuff tear and that if he/she surgically repairs your cuff tear you will improve and that the cuff is torn again at 2-year follow-up in 29\% of the cases where surgery is done. Would you choose surgery? Yes or No

Age, gender, the shoulder affected and the functional status assessed through the Constant score were also recorded.
\end{abstract}

Results: 80 patients were randomized (43 to group A and 37 to group B). The patients assigned to group A (benefit) accepted surgery significantly more frequently than those assigned to group B (complication) $(P=0.000)$. In group A, 36 of 43 (84\%) accepted surgery, compared to 17 of 37 (46\%) in group B.

Conclusions: The way that information on rotator cuff disorders is provided strongly influences patients' treatment decisions.

Trial registration: ClinicalTrials.gov, NCT03205852. Registered 29 June 2017. Retrospectively registered.

Keywords: Patient participation, Shared decision-making, Outcomes, Rotator cuff, Rotator cuff-repair

\footnotetext{
* Correspondence: 86925@parcdesalutmar.cat

'Department of Orthopedics, Hospital del Mar, Passeitg Marítim 25-29, 08003

Barcelona, Spain

Full list of author information is available at the end of the article
}

(c) The Author(s). 2019 Open Access This article is distributed under the terms of the Creative Commons Attribution 4.0 International License (http://creativecommons.org/licenses/by/4.0/), which permits unrestricted use, distribution, and reproduction in any medium, provided you give appropriate credit to the original author(s) and the source, provide a link to the Creative Commons license, and indicate if changes were made. The Creative Commons Public Domain Dedication waiver (http://creativecommons.org/publicdomain/zero/1.0/) applies to the data made available in this article, unless otherwise stated. 


\section{Introduction}

The paternalistic approach to treatment decision-making based on the doctor's preferences has largely been superseded by involving patients throughout the decision-making process where possible. Moreover, it has been shown that patient involvement results in more cost-effective services and improves health outcomes, quality of life and patient satisfaction [1-7].

Most health conditions can be approached with different strategies that have implicit advantages and disadvantages. Rotator cuff disorders often have various conservative and surgical approaches, each with their own risks and benefits [8]. Many studies have emerged in recent years to determine the optimal degree of involvement for patients, how patients make treatment choices and factors solely related to the physician that affect patient participation [1-3, 6, 7, 9-16].

It seems crucial to provide the patient with information about the pros and cons of different treatment strategies and share treatment decision-making. However, little information is provided on how this information should be structured. Should we give the patient information based on the benefits or should we give the information based on the complications of the treatment?
The objective of this study was to evaluate the effect on patient treatment decision-making if information was given based on the benefit or on the complications in rotator cuff disorders. A secondary objective was to examine the association of socio-demographic variables and functional impairment in the patient decisions.

\section{Materials and methods}

A prospective randomized study was conducted of patients diagnosed with rotator cuff tears who had been recruited at their first clinical visit. The rotator cuff tears were documented with magnetic resonance imaging (MRI) in all patients. Patients were excluded if they had had previous shoulder surgery, worker's compensation, or were unwilling to participate.

Patients were recruited from July to December 2014 in a single tertiary referral hospital. One hundred and eleven patients attended the Shoulder Unit for their first clinical visit during the recruitment period. Twenty-seven were excluded due to previous shoulder surgery and 4 were excluded as recipients of worker's compensation. Eighty patients ultimately met the inclusion criteria (Fig. 1).

Randomization was performed with the aid of a computer-generated list with no restrictions. A nurse

Assessed for eligibility $(n=111)$

31 excluded

(27 previous surgery

4 workers compensation)

Randomized $(n=80)$

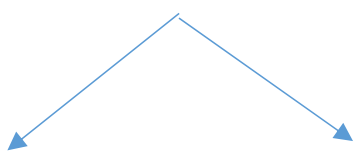

Allocated to group $A(n=43)$

Allocated to group $B(n=37)$

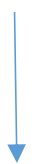

Analyzed in group $A(n=43)$

Analyzed in group $B(n=37)$

Fig. 1 Flow diagram of the progress through the phases of a parallel-randomized trial of two groups 
assigned new patients to either to group A or B, depending on the computer-generated list, before the clinical visit. The nurse asked the patients to complete a questionnaire before entering the office. The questionnaire included epidemiological data such as age and gender, clinical scenario A or B depending on the randomization, and the question to either accept or decline surgery. No information that could be used to identify the patient was recorded. The nurse administered the questionnaire on the first clinical visit after explaining that this was a study on patient decision-making to each patient, that it was anonymous and had no implication for treatment, and that involvement could be declined. The same doctor examined all the patients to minimize bias related to doctor attitude. Only oral information was given to both groups without any printed support. The key messages were that a torn cuff could be treated either conservatively or surgically.

The patients were randomly allocated to either group A (benefit) or group B (complication) and were asked to answer the following questions based on their assigned group:

Group A (benefit): Your doctor informs you that you have a rotator cuff tear and states that if he/she surgically repairs your cuff tear you will improve and that the cuff remains healed at the 2-year follow-up in $71 \%$ of the cases where surgery is done.

\section{Would you choose surgery? Yes or No}

Group B (complication): Your doctor informs you that you have a rotator cuff tear and that if he/she surgically repairs your cuff tear you will improve and that the cuff is torn again at 2-year follow-up in 29\% of the cases where surgery is done.

\section{Would you choose surgery? Yes or No}

The data used to construct the question was obtained by arbitrarily choosing the study by Boileau et al. in which the authors declared that they obtained complete healing of the rotator cuff in $71 \%$ of the patients who underwent arthroscopic repair of full-thickness tears of the supraspinatus [17].

Age, gender, the shoulder affected, and the functional status assessed using the Constant score were also recorded [18]. The Constant score is a functional scale that includes subjective and objective data. Subjective data includes pain assessment ( $0-15$ points) and daily living activities ( $0-20$ points). Objective assessment includes range-of-motion (forward elevation, abduction, lateral rotation, and internal rotation) ( $0-40$ points $)$ and strength ( $0-25$ points).

\section{Statistics}

The power calculation for the sample size was based on an estimated reduction of $25 \%$ in the agreement to accept surgery, accepting an alpha risk of 0.05 and a beta risk inferior to 0.2 . Forty patients were needed in each group to detect a significant difference between the two groups if the presence of the effect in group 1 was 0.6 and was 0.85 in group 2 using an ARCSINUS approximation test. Categorical variables are described with frequencies and percentages, and continuous variables are expressed as mean and standard deviations (SD). Comparisons of categorical variables between groups were assessed with the chi-square or Fisher exact tests, as appropriate. Quantitative variables were compared via the Mann-Whitney $U$ test. $P$ values of $<0.05$ were considered statistically significant. Analyses were performed using the SPSS 18.0 software package (SPSS Inc., Chicago, IL, USA).

The study was approved by the Ethics Committee and all included patients provided signed informed consent.

\section{Results}

There were 44 females and 36 males. The mean age was 50.8 years (ranging from 23 to 80 ). In 49 patients, the right shoulder was affected and the left shoulder in 31 patients. Forty-three patients were allocated to group A (benefit) and 37 to group B (complication). The mean age of the patients in group A was 50.8 years old and 54.5 years in group B. In group A, there were 29 females and 14 males while there were 25 females and 12 males in group B. The mean Constant score total was 62.3 for the patients included in group A and 58.2 for the patients in group B.

The overall results showed a significant difference $(P=0.000)$ between groups relative to their acceptance of surgery. Thirty-six out of the $43(84 \%)$ of patients included in group A (benefit) accepted surgery compared to 17 out of the 37 (46\%) in group B (complication).

Age, gender, the shoulder affected, and the functional status assessed by Constant score did not significantly differ between the patients accepting or refusing surgery (Table 1).

\section{Discussion}

There is an increasing trend towards sharing the different treatment options with the patient and involving the patient in treatment decision-making [1-7]. This study demonstrates that doctors can significantly influence a patient's decision depending on the content of the information provided. In rotator cuff disorders, most patients agree to receive surgery if the doctor presents information covering the basis of the benefits of surgery. On the other hand, most patients refuse to receive surgery if information is provided based on the negative outcomes of 
Table 1 Characteristics of patients accepting surgery compared to those refusing surgery

\begin{tabular}{llll}
\hline & $\begin{array}{l}\text { Accepting surgery } \\
\text { Yes }\end{array}$ & $\begin{array}{l}\text { Accepting surgery } \\
\text { No }\end{array}$ & $P$ value \\
\hline Question & & & \\
Benefit & $36 / 43(83.7 \%)$ & $7 / 43(16.3 \%)$ & \\
Side effect & $17 / 37(45.9 \%)$ & $20 / 37(54.1 \%)$ & 0.000 \\
Age & 50.8 & 54.5 & 0.35 \\
Gender & & & \\
$\quad$ Female & $66.7 \%$ & $33.3 \%$ & \\
$\quad$ Male & $65.9 \%$ & $34.1 \%$ & 0.94 \\
Laterality & & & \\
$\quad$ Right & $67.3 \%$ & $32.7 \%$ & 0.79 \\
$\quad$ Left & $64.5 \%$ & $35.5 \%$ & 0.50 \\
Constant score & 62.3 & 58.2 & 0.89 \\
Pain & 6.8 & 6.8 & 0.57 \\
DLA & 13.5 & 12.9 & 0.43 \\
FE & 8.4 & 7.9 & 0.46 \\
ABD & 8.3 & 7.8 & 0.27 \\
LR & 7.4 & 6.3 & 0.66 \\
IR & 7.2 & 7 & 0.45 \\
Strength & 10 & 8.9 & \\
\hline DLA & & & \\
\hline
\end{tabular}

$D L A$ daily living activities, $F E$ forward elevation, $A B D$ abduction, $L R$ lateral rotation, IR internal rotation

surgery, such as the cuff may be torn again at 2-year follow-up.

Not all physicians are in favor of involving patients in treatment decisions, especially less-experienced physicians. They are the ones who more frequently report barriers to involving patients [13]. Another commonly expressed barrier is the lack of time to share treatment decisions [13]. Nevertheless, it has been demonstrated that physicians are poor at assessing a patient's preferences and that informed patients often tend to choose treatment strategies other than what the doctors suggest $[11,19]$.

From the patient's perspective, not all want to be involved in treatment decision-making. Factors such as age, gender, educational level, urban or rural residence, and the severity of the illness play an important role in the decision $[4,9]$. The Control preferences scale has been widely used to determine if the patient prefers an active, passive, or collaborative role in treatment decision [20]. Working on patient-reported outcomes rather than on functional scores and sharing this information with the patients as well as using it in the treatment decision-making process may be the path for the future [1].

There is no consensus about the best treatment strategy for rotator cuff disorders [21, 22]. While some authors recommend conservative treatment, others advocate for surgical repair of the torn cuff [8]. Among others, the re-tear rate after surgical treatment is a common complication that can impair outcomes [17]. Indications for rotator cuff repair have been defined from the physician's perspective. These include age, gender, range-of-motion, weakness in forward elevation, tear size, and worker's compensation status [8, 23, 24]. There is a lack of agreement among orthopedic surgeons relative to the indications for rotator cuff surgery. Surgeons who perform a higher volume of cuff repairs are more likely to agree to perform surgery [4]. From the patient's perspective, psychological distress, depression, anxiety, and mental health seem to affect the outcome of rotator cuff treatments [24-28]. Moreover, whenever patient expectations were met after cuff repair, satisfaction, and quality of life improved [29, 30].

After all the aforementioned, it seems logical to involve the patient in the treatment decision-making for rotator cuff disorders but little attention has been paid to the way doctors inform patients so as to reach a decision. In the present study, it has been demonstrated that doctors can significantly influence a patient's decision regarding rotator cuff surgery depending on the way they deliver the information. If information is presented based on the benefits of rotator cuff surgery, the majority of patients may accept surgery. Then again, most patients may refuse surgery if the information given focuses on the disadvantages of surgery. We cannot go about sharing information with patients and/or involving them in treatment decisions unless we are able to properly structure the information we provide and be sure that the information itself will not create a biased decision. It has been demonstrated, in urologic disorders, that the adverse effect profile of treatment is very important when deciding on the management of benign diseases, whereas treatment efficacy is more relevant in the management of life-threatening illness [10]. Full surgical information, including the characteristics of the arthroscopic technique, total length that the patient will need to be in-hospital until discharge, immobilization period, expected length of the rehabilitation process, and the time expected to fully recover and eventually to return to work, should be carefully explained to the patient.

In the present study, the level of pain or functional impairment, recorded using the Constant score, did not significantly differ between patients accepting or rejecting surgery. This suggests that the way that information is provided has a stronger influence on a patient's treatment decision than the pain or functional impairment that the patient perceives. In the same manner, age, gender, and the shoulder affected did not significantly affect patients' treatment decisions. 
More research is needed on advising how to give information to patients and share treatment decision-making in rotator cuff disorders. Additionally, the development of decision-making support tools to help patients to make a decision for surgery or not in rotator cuff disorders should be considered as a potential solution.

The limitations of the study include the arbitrary selection of the Boileau et al. study to obtain the data to construct the question and that many factors can influence a patient's decision. Despite these limitations, the randomized nature of the study provided a relatively equal distribution of various characteristics in both study groups that could potentially affect patient decisions. According to the sample size calculation, 40 patients were needed in each group. Eighty patients were included. Because of the randomization process, group A had 43 patients and group B had 37 patients, but the differences between both groups were wide enough to accept 37 patients in group B.

\section{Conclusions}

The content of the information given to the patient influences their choice relative to treatment decision-making in rotator cuff surgery. Further research is needed to evaluate the effect of providing complete information to patients (specifying both sides, positive and negative) as well as the development of decision-making support tools that aid in choosing whether to do surgery or not for a rotator cuff disorder.

\section{Abbreviations}

MRI: Magnetic resonance imaging

Funding

No funding

\section{Availability of data and materials}

Please contact author for data requests

\section{Authors' Contributions}

$C T, F S$, and JM collaborated in the data analysis, data interpretation and writing process. All the authors have read and approved the final manuscript

\section{Ethics approval and consent to participate}

The study was approved by the Ethical Committee of Comité Etico de Investigación Clínica del Parc de Salut Mar with the number 2014/5625/I. All the patients included signed informed consent.

\section{Consent for Publication}

Not applicable

\section{Competing interests}

The authors declare that they have no competing interests.

\section{Publisher's Note}

Springer Nature remains neutral with regard to jurisdictional claims in published maps and institutional affiliations.

\section{Author details}

${ }^{1}$ Department of Orthopedics, Hospital del Mar, Passeitg Marítim 25-29, 08003 Barcelona, Spain. ²Department of Orthopedics, Hospital d'Igualada, Consorci Sanitari I'Anoia, Barcelona, Spain.

Received: 21 August 2018 Accepted: 16 April 2019

Published online: 29 April 2019

\section{References}

1. Baumhauer JF, Bozic KJ. Value-based healthcare: patient-reported outcomes in clinical decision making. Clin Orthop Relat Res. 2016;474:1375-8.

2. Coulter A. Partnerships with patients: the pros and cons of shared clinical decision-making. J Health Serv Res Policy. 1997:2:112-21.

3. Dolan JG. Multi-criteria clinical decision support: a primer on the use of multiple criteria decision making methods to promote evidence-based, patient-centered healthcare. Patient. 2010;3:229-48.

4. Elkin EB, Kim SHM, Casper ES, et al. Desire for information and involvement in treatment decisions: elderly cancer patient's preferences and their physicians' perceptions. J Clin Oncol. 2007;25:5275-80.

5. Mulley AG, Trimble C, Elwyn G. Stop silent misdiagnosis: patients' preferences matter. BMJ. 2012;345:e6572.

6. Singh J, Sloan JA, Atherton PJ, et al. Preferred roles in treatment decision making among patients with cancer: a pooled analysis of studies using control preferences scale. Am J Manag Care. 2010:16:688-96.

7. Vahdat S, Hamzehgardeshi L, Hessam S, et al. Patient involvement in health care decision making: a review. Iran Red Cres Med J. 2014;16:e12454.

8. Oh LS, Wolf BR, Hall MP, et al. Indications for rotator cuff repair. Clin Orthop Relat Res. 2006:455:52-63.

9. Degner LF, Sloan JA. Decision making during serious illness: what role do patients really want to play? Clin Epidemiol. 1992;45:941-50.

10. Hellenthal N, Ellison L. How patients make treatment choices. Nature Clinical Practice. 2008;5:426-33

11. Robinson A, Thomson R. Variability in patient preferences for participating in medical decision making: implication for the use of decision support tools. Quality in Health Care. 2001;10(suppl I):i34-8.

12. Schildmann J, Grunke M, Kalden JR, et al. Information and participation in decision-making about treatment: a qualitative study of the perceptions and preferences of patients with rheumatoid arthritis. J Med Ethics. 2008:34:775-9.

13. Shepherd HL, Tattersall MHN, Butow PN. Physician-identified factors affecting patient participation in reaching treatment decisions. J Clin Oncol. 2008:26:1724-31.

14. Sturgess J, Clapp JT, Fleisher LA. Shared decision-making in peri-operative medicine: a narrative review. Anaesthesia. 2019:74:13-9.

15. Elwyn $\mathrm{G}$, Frosch DL, Kobrin S. Implementing shared decision-making: consider all the consequences. Implementation Science. 2016;11:114.

16. Kilbride MK, Joffe $S$. The new age of patient autonomy: implications for the patient-physician relationship. JAMA. 2018:320:1973-4.

17. Boileau P, Brassart N, Watkinson DJ, et al. Arthroscopic repair of fullthickness tears of the supraspinatus: does the tendon really heal? J Bone Joint Surg. 2005;87-A:1229-40.

18. Constant $\mathrm{CR}$, Murley $\mathrm{AH}$. A clinical method of functional assessment of the shoulder. Clin Orthop Relat Res. 1987;214:160-4.

19. Straub C, Nebling T, Müller H. Translating research into practice: a German sickness fund supporting patient participation. Patient Educ Couns. 2008;73:544-50.

20. Degner LF, Sloan JA, Venkatesh P. The control preferences scale. Can J Nurs Res. 1997;29:21-43.

21. Thorpe A, Hurworth M, O'Sullivan P, et al. Rotator cuff disease: opinion regarding surgical criteria and likely outcome. ANZ J Surg. 2017:87:291-6.

22. Littlewood C, Rangan A, Beard DJ, et al. The enigma of rotator cuff tears and the case for uncertainty. Br J Sports Med. 2018;52:1222.

23. Dunn WR, Schackman BR, Walsh C, et al. Variation in orthopaedic surgeon's perceptions about the indications for rotator cuff surgery. J Bone Joint Surg 2005;87-A:1978-84.

24. Lambers Heerspink FO, Dorrestijn O, van Raay JJAM, et al. Specific patientrelated prognostic factors for rotator cuff repair: a systematic review. J Shoulder Elbow Surg. 2014;23:1073-80.

25. Cho $\mathrm{CH}$, Seo HJ, Bae KC, et al. The impact of depression and anxiety on selfassessed pain, disability, and quality of life in patients scheduled for rotator cuff repair. J Shoulder Elbow Surg. 2013;22:1160-6. 
26. Potter MQ, Wylie JD, Granger EK, et al. One-year patient-reported outcomes after arthroscopic rotator cuff repair do not correlate with mild to moderate psychological distress. Clin Orthop Relat Res. 2015;473:3501-10.

27. Potter MQ, Wylie JD, Greis PE, et al. Psychological distress negatively affects self-assessment of shoulder function in patients with rotator cuff tears. Clin Orthop Relat Res. 2014;472:3926-32.

28. Wylie JD, Suter T, Potter MQ, et al. Mental health has a stronger association with patient-reported shoulder pain and function than tear size in patients with full-thickness rotator cuff tears. J Bone Joint Surg. 2016;98:251-6.

29. Henn RF III, Tashijian RZ, Kang L, et al. Patient's preoperative expectations predict the outcome of rotator cuff repair. J Bone Joint Surg. 2007:89:1913-9.

30. Tashjian RZ, Bradley MP, Tocci S, et al. Factors influencing patient satisfaction after rotator cuff repair. J Shoulder Elbow Surg. 2007;16:752-8.

Ready to submit your research? Choose BMC and benefit from:

- fast, convenient online submission

- thorough peer review by experienced researchers in your field

- rapid publication on acceptance

- support for research data, including large and complex data types

- gold Open Access which fosters wider collaboration and increased citations

- maximum visibility for your research: over $100 \mathrm{M}$ website views per year

At BMC, research is always in progress.

Learn more biomedcentral.com/submissions 